\title{
К вопросу применения рефрактометрии для мониторинга процесса брожения сусла
}

Руслан Генрихович Тимофеев, канд. техн. наук, доцент, вед. науч. сотр. лаборатории тихих вин, Russ1970@mail.ru Федеральное государственное бюджетное учреждение науки «Всероссийский национальный научно-исследовательский институт виноградарства и виноделия «Магарач» РАН», Россия, Республика Крым, 298600, г. Ялта, ул. Кирова, 31

Изучены закономерности изменения показаний сахарной шкалы рефрактометра в процессе спиртового брожения виноградного сусла. Экспериментально установлены эмпирические зависимости между плотностью сусла и показаниями сахарной шкалы рефрактометра в процессе брожения сусла. Установлен практический выход спирта из единицы сахаров для различных фаз брожения. Предложена методика контроля процесса спиртового брожения виноградного сусла, основанная на использовании рефрактометрии.

Ключевые слова: виноделие; методы контроля; денсиметрия; выход спирта.
O R I G I N A L R E S E A R C H

\section{On the use of refractometry to monitor must fermentation processes}

Ruslan Genrihovich Timofeev

Federal State Budget Scientific Institution All-Russian National Research Institute of Viticulture and Winemaking Magarach of RAS, 31 Kirova Street, 298600 Yalta, Republic of Crimea, Russia

Refractometer sugar scale variability patterns have been studied in the process of grape must alcoholic fermentation. Empirical relationships between must density and refractometer sugar scale indications were experimentally established in the process of must fermentation. The isolated alcohol output from a sugar unit was established for various fermentation phases. A refractometry based method to control the grape must alcoholic fermentation process was proposed.

Key words: winemaking; control methods; densimetry; alcohol yield.

го экстракта) от пмотности в процессе брожения имеет виА [2]:

$$
\mathrm{C}=\mathrm{C}_{0}-\frac{\rho_{0}-\rho}{0,453},
$$
в сусле перед брожением, а также мониторинга снижения их концентрации в процессе спиртового брожения в виноделии используют Аенсиметрический (ареометриче-

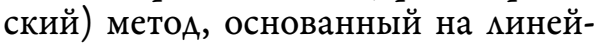
ной зависимости плотности сусла от концентрации сахаров. Пцотность свежевыжатого виноградного сусла Ао брожения однозначно, с точностью 5 г/ $\mathrm{AM}^{3}$, опреАемяет массовую концентрацию сахаров $[1$, C.26]. В процессе спиртового брожения плотность сусла уменьшается пропорционацьно комичеству выброАивших сахаров. Аля оценки концентрации сахаров в процессе брожения Аенсиметрическим методом необходимо знать исходную пиотность сусла до брожения. Зависимость концентрации сахаров (обще-

гАе $\mathrm{C}$ и $\mathrm{C}_{0}$ - искомая и начацьная концентрация сахаров (экстракта) в сусле, г/AM ${ }^{3}, \rho_{0}$ и $\rho-$ начамьная и отвечающая искомой сахаристости

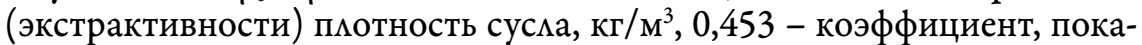
зывающий снижение плотности сусла при сбраживании 1 г/ AM $^{3}$ сахаров, соответственно.

Если при измерении плотности исходного сусла особых труАностей не возникает, то в процессе брожения сусло в значитемьной степени насыщено углекислотой, что обуславливает ряд проблем связанных с точным определением его плотности, а именно, наличие пузырьков газа в жилкой фазе, а так же аАсорбция пузырьков газа на поверхности ареометра обуславцивают кажущееся снижение плотности жиАкости. Обимьное пенообразование, намичие взвесей и дрожжевых кметок де-

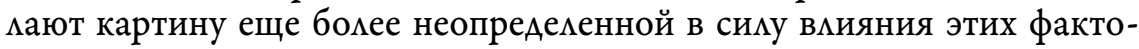
ров. Аця нивемирования этого эффекта можно проводить частичную Аегазацию образца перед определением плотности, удацять пузырьки газа путем вращения ареометра, использовать ареометры больших типоразмеров, что усложняет оперативный мониторинг процесса брожения. ОАним из неАостатков денсиметрического метода также явцяется необходимость использования большого объема (порядка 250 ми) образца, что не всегАа возможно при контроце процесса в мацом объеме, в частности в исследовательских целях.

Ацьтернативой денсиметрическому методу определения концентрации сахаров в сусле Ао брожения является рефрактометрический метод [1, С.27], который позвоцяет проводить определение концентрации сахаров в пробе объемом поряАка 0,1 ми. ИсслеАования возможностей рефрактометрии Аля мониторинга процесса брожения сусла было изучено А.С. Вечером еще в 1958 году [3], оАнако, несмотря на Аовоцьно подробные проведенные исследования, Аанная проблема Аалека до помного разрешения в плане практического применения в энохимической практике.

Согласно представлениям, заложенным в основу рефрактометрических методов анамиза, в идеацьных системах (образующихся без из- 
менения объема и поляризуемости компонентов) зависимость показателя преломления n смеси от состава близка к прямоминейной, если состав выражен в объемных домях (процентах) [4]. Аанный факт заложен в основу рефрактометрических методов определения сухих веществ в продуктах переработки плодов и овощей [5], а также, наряду с Аенсиметрическим методом, Аһя оценки массовой концентрации экстракта и сахаров в виноградном сусле до брожения [6]. Рефрактометрию также

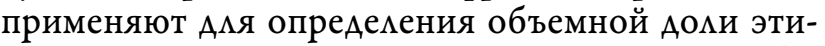

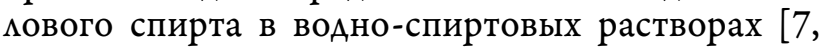
8], гАе показатель преломления воАно-спиртовой смеси оАнозначно опредемяет концентрацию этанола в Аиапазоне от 0 Ао $50 \%$ об.

Объем, который занимает еАиница массы бомьшинства растворимых веществ в растворе, в частности, вещества экстракта виноградного сусла, не зависит от его концентрации, что объясняет $\Lambda$ инейный характер зависимости плотности растворов от их концентрации. В случае растворов этицового спирта объем, который он занимает в растворе, зависит от его концентрации неминейно, что выражается в том, что функция плотности водно-спиртовых растворов также имеет неминейный характер.

В процессе спиртового брожения сусла происходит уменьшение концентрации редуцирующих сахаров и увемичение концентрации этимового спирта. Из оАной молекулы гексозы образуются Аве молекулы этилового спирта и Аве моцекулы углекислоты. Учитывая молекумярные массы гексоз и этилового спирта, из 1 г сахаров теоретически можно получить 0,5114 г $\left(0,6479 \mathrm{~cm}^{3}\right)$ чистого этанола. Реацьный выход этанола ниже в симу вцияния разАичных факторов, основными из которых явмяются образование побочных продуктов брожения, унос спирта с углекислотой, использование части сахаров в процессе накопления Арожжами биомассы, так что величина $0,6 \mathrm{~cm}^{3}$ образовавшегося спирта из 1,0 г сахаров, используемая в технологических расчетах $[2,9]$, явцяется величиной скорее нормативной, чем отражающей реацьный выход спирта в каждый текущий момент времени. Если рассматривать процесс упрощенно, то можно преАположить, что на кажАую еАиницу снижения концентрации реАуцирующих сахаров сусла образуется определенный объем спирта, что Аолжно, теоретически, приводить к минейному изменению показателя премоммения сусла в процессе брожения пропорционацьно количеству выбродивших сахаров.

Цемью настоящей работы является установление закономерностей изменения показаний сахарной шкацы рефрактометра в процессе брожения виноградного сусла и разработка метода контроля процесса брожения по изменению показаний сахарной шкамы рефрактометра.

\section{Объекты и методы исследований}

В качестве материала Аля исследования быми использованы образцы сусла винограда сорта

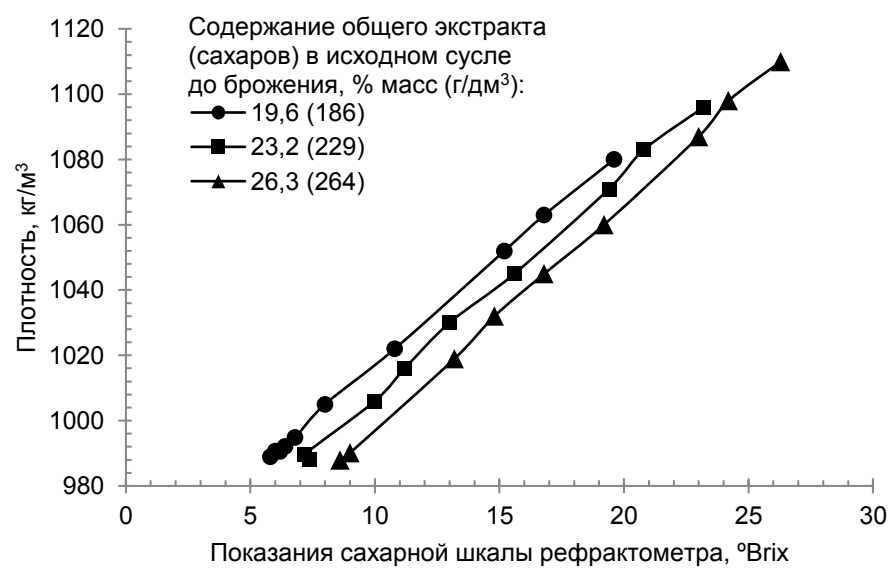

Рис. 1. Связь между плотностью сусла и показаниями сахарной шкалы рефрактометра в процессе спиртового брожения для разной начальной сахаристости сусла

Fig. 1. The relationship between grape must density and readings of the refractometer sugar scale in the process of alcoholic fermentation for different initial sugar content in the must

Шабаш и Мускат бемый урожая 2018 года с массовой концентрацией сахаров от 150 г/AM Aо $^{3}$ А00 г/Ам ${ }^{3}$. Всего 8 образцов сусла. Брожение образцов проводими используя pacy $47-\mathrm{K}$.

Методика исследований закиючалась в следующем. В сульфитированном Ао 75 мг/Ам ${ }^{3}$ осветленном сусле определяли массовую концентрацию сахаров, плотность, а также массовую Аолю сухих веществ в пересчете на сахарозу рефрактометрически. Аалее в сусло вносими разводку чистой кумьтуры Арожжей и после появления признаков брожения производими контромь процесса брожения с периодичностью 2-3 суток по слеАующим показателям:

- плотность - ареометрическим методом;

- массовую концентрацию сахаров - методом Бертрана по ГОСТ 13192-73 [10];

- объемную Аолю этилового спирта - методом отгона по ГОСТ 32095-2013[11];

- показатель премомления по сахарной шкале рефрактометра УР $\Lambda-2$ при температуре $(20 \pm 0,5)^{\circ} \mathrm{C}$.

\section{Результаты исследования и их обсуждение}

В результате проведенных исследований было установ ено, что в процессе спиртового брожения происхоАит снижение показаний сахарной шкамы рефрактометра пропорционацьно снижению его пцотности (рис. 1).

Результат обработки данных эксперимента Аац следующую эмпирическую формулу Аля выражения зависимо сти межАу этими вемичинами:

$$
\begin{aligned}
\rho & =\left(0,0342 \times \mathrm{B}_{0}+6,049\right) \times \mathrm{B}+969,72+ \\
& +0,66 \times \mathrm{B}_{0}-0,086 \times \mathrm{B}_{0}^{2},
\end{aligned}
$$

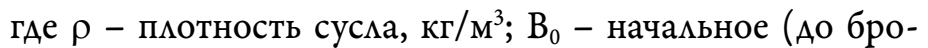
жения) показание сахарной шкамы рефрактометра, В показание сахарной шкалы рефрактометра в процессе брожения.

При $\mathrm{B}=\mathrm{B}_{0}$ получаем выражение Аля плотности сусла $\left(\kappa г / \mathrm{M}_{3}\right)$ Ао начама спиртового брожения исходя из показаний сахарной шкамы рефрактометра:

$$
\rho_{0}=969,72+6,709 \times \mathrm{B}_{0}-0,05158 \times \mathrm{B}_{0}{ }^{2},
$$

тогАа Аһя массовой концентрации экстракта Ао брожения, г/ $\mathrm{AM}^{3}$ можно записать смеАующее выражение: 
$\exists_{0}=\frac{\rho_{0} \times 10 \times \mathrm{B}_{0}}{1000}=\frac{969,72 \times \mathrm{B}_{0}+6,709 \times \mathrm{B}_{0}{ }^{2}-0,05158 \times \mathrm{B}_{0}{ }^{3}}{100}$. (4)

Аанные выражения (2-4) Аця плотности и кон-

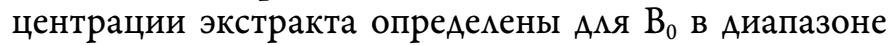
$(10-30)^{\circ}$ Brix.

Таким образом, зная показания сахарной шкамы рефрактометра Ао начаца брожения и, следовательно, содержание сахаров в исходном сусле, например, испомьзуя специацьные таблицы, приведенные в $[1,6]$, а также плотность сусла Ао и в процессе брожения, вычисленные по формулам (3) и (2), соответственно, можно контролировать содержание сахаров по показаниям сахарной шкалы рефрактометра используя формулу (1). Следует отметить, что при измерении показателя преломления образец сусла следует профильтровать через шприцевой фимьтр, так как намичие посторонних вкцючений (взвеси, Арожжевые кметки) в сусле привоАит к тому, что поА Аействием силы тяжести они оседают на призме рефрактометра и Аелают нечеткой границу межАу светом и тенью при снятии показаний. Можно обойтись без преАварительной фильтрации образца, но в этом случае призму рефрактометра, если это технически возможно, следует повернуть так, чтобы посторонние частицы не осеАами на ней под Аействием симы тяжести.

На основании данных эксперимента были вычисмены значения коэффициента выхода спирта из еАиницы сахаров $\mathrm{cm}^{3} / г$, в зависимости от степени выбраживания сусла и начацьной сахаристости сусла. Эти Аанные представцены на рис. 2.

На первом этапе брожения коэффициент выхода спирта возрастает до определенного цокального максимума, затем происходит некоторое его снижение, а затем снова возрастает в конце брожения. Аанная кривая изменения коэффициента выхода спирта явцяется накопительной характеристикой, т.к. суммирует выхоА, который бым получен на

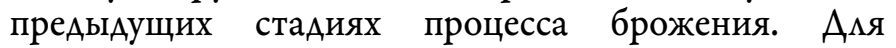
Аостижения величины 0,6 и выше (см. например, кривую с начацьной концентрацией сахаров 260

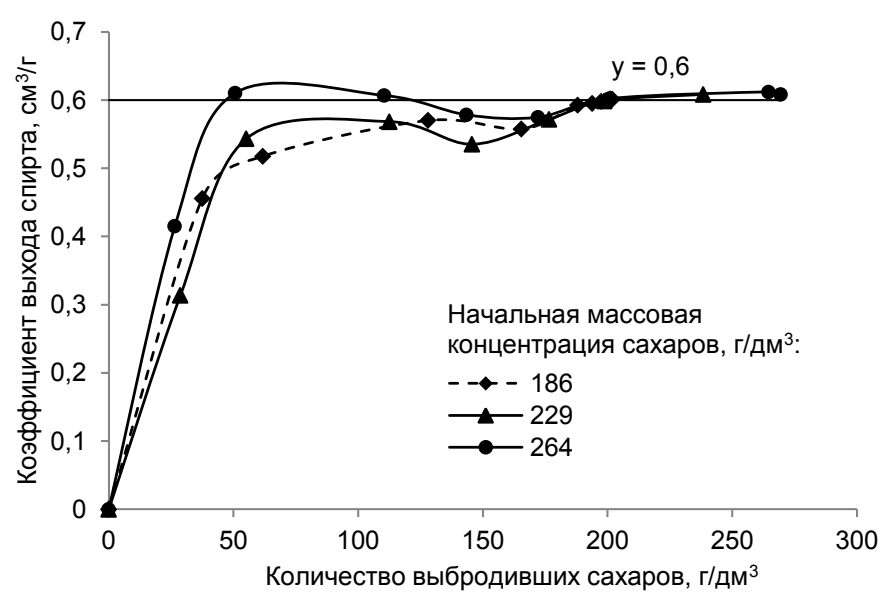

Рис. 2. Изменение коэффициента выхода спирта из единицы сахаров в зависимости от количества выбродивших сахаров для сусла с различной начальной массовой концентрацией сахаров

Fig. 2. The change in the alcohol yield ratio from a unit of sugars depending on the amount of fermented sugars for the must with a varied initial sugar mass concentration

Таблица 1. Зависимость коэффициента выхода спирта от количества выбродивших сахаров для виноградного сусла с начальной массовой концентрацией сахаров $160-270$ г/дм ${ }^{3}$

Table 1. The dependence of the alcohol yield ratio on the amount of fermented sugars for grape must with an initial mass concentration of sugars $160-270 \mathrm{~g} / \mathrm{dm}^{3}$

\begin{tabular}{|c|c|c|}
\hline \multirow{2}{*}{$\begin{array}{l}\text { Количество } \\
\text { выброженных саха- } \\
\text { ров, г/Ам }\end{array}$} & \multicolumn{2}{|c|}{ Коэффициент выхода спирта см³/г } \\
\hline & $\begin{array}{l}\text { среднее } \\
\text { значение }\end{array}$ & $\begin{array}{l}\text { Аоверите ьный } \\
\text { интервац }\end{array}$ \\
\hline 30 & 0,4 & $\pm 0,12$ \\
\hline 50 & 0,54 & $\pm 0,1$ \\
\hline 80 & 0,58 & $\pm 0,04$ \\
\hline 150 & 0,56 & $\pm 0,03$ \\
\hline 200 и выше & 0,6 & $\pm 0,01$ \\
\hline
\end{tabular}

г/ $\mathrm{AM}^{3}$ ) при количестве выбродивших сахаров 50100 г/ AM $^{3}$, скорость продукции этанола на отрезке от 30-50 г/AM АО Ажна значите ьно превышать скорость ассимимяции сахаров, и накопмение этанома вызвано потреблением накопиенных Арожжевыми кцетками метаболитов, что подтверждает теорию стадийности биохимических процессов в кметке. Анациз экспериментацьных Аанных также показац, что, несмотря на значительно меньшее количество образовавшегося спирта на первом этапе брожения, снижение плотности, бымо пропорционацьно снижению массовой концентрации сахаров, определенных по ГОСТ 13192-73 с таким же инкрементом, что и в середине и в конце брожения, что свидетельствует о том, что характер образующихся продуктов брожения на этапе разбраживания и накопления биомассы Арожжей несколько иной, чем в сереАине и конце брожения, и эти продукты брожения не вносят вкмаА в изменение плотности отгона при определении объемной Аоли этимового спирта по ГОСТ 32095-2013.

Среднее значение и 95\%-ный доверительный интервац Аля выхода спирта из еАиницы массы сахаров в процессе спиртового брожения осветленного сусла расой $47 К$, полученный на основании обработки экспериментацьных данных, приведен в табл. 1.

В технологии виноградных вин может возникнуть потребность вычислить показания сахарной шкалы рефрактометра, при достижении определенной массовой концентрации сахаров, например, с цемью приготовцения вин с прерванным процессом спиртового брожения (столовые полусухие, полумаАкие, а также микерные вина).

Анализ структуры формулы (2) показац, что ее

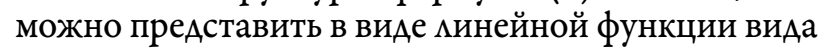

$$
\rho=K\left(B_{0}\right) \times B+L\left(B_{0}\right),
$$

т.е. при заданном начацьном значении $\mathrm{B}_{0}$, зависимость пцотности от показаний сахарной шкацы рефрактометра имеет минейный характер. С Аругой стороны, существует минейная зависимость межАу снижением плотности сусла при брожении и массовой концентрацией выбродивших сахаров согласно формуле (1). Исходя из этого можно записать 


$$
\frac{\rho-\rho_{0}}{0,453}=\frac{B_{0}-B}{X},
$$

гАе $\mathrm{x}$ - изменение показаний сахарной шкамы рефрактометра при снижении массовой концентрации сахаров на $1 \mathrm{\Gamma} / \mathrm{AM}^{3}$.

Тогда Аця массовой концентрации сахаров (экстракта) в процессе брожения можно записать:

$$
\mathrm{C}=\mathrm{C}_{0}-\frac{\mathrm{B}_{0}-\mathrm{B}}{\mathrm{X}\left(\mathrm{B}_{0}\right)}=\mathrm{C}_{0}-\left(\mathrm{B}_{0}-\mathrm{B}\right) \times \frac{1}{\mathrm{X}\left(\mathrm{B}_{0}\right)},
$$

гАе $\mathrm{C}$ и $\mathrm{C}_{0}$ - массовая концентрация сахаров (экстракта) в процессе брожения и до брожения, соответственно, гАм ${ }^{3} ; \mathrm{B}_{0}$ и $\mathrm{B}$ - показания сахарной шкамы рефрактометра Ао и в процессе брожения, о Brix; $1 / \mathrm{X}\left(\mathrm{B}_{0}\right)$ коэффициент пропорционацьности межАу снижением массовой концентрации сахаров и изменением показаний сахарной шкамы рефрактометра.

Вычисленные Аля разных значений $\mathrm{B}_{0}$ величины $\mathrm{C}_{0}, \alpha\left(\mathrm{B}_{0}\right)=1 / \mathrm{X}\left(\mathrm{B}_{0}\right)$ приведены в табц. 2 .

Продемонстрируем полученные закономерности Аля технологических расчетов.

Пример. Исходные показания сахарной шка-

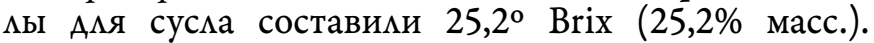
После остановки брожения холодом и фимьтрацией показания сахарной шкалы составими $10^{\circ}$ Brix. Определить концентрацию общего экстракта и сахаров до брожения, после остановки брожения и количество образовавшегося этанола.

Опредемяем концентрацию экстракта $Э_{0}$ Ао брожения по формуле (4)

$\exists_{0}=\frac{969,72 \times 25,2+6,709 \times 25,2^{2}-0,05158 \times 25,2^{3}}{100} \cong 278, \Gamma / \mathrm{AM}^{3}$

Массовую концентрацию сахаров в сусле до брожения определяем из табл. 2, что составит 252 г/ АM $^{3}$.

Концентрацию общего экстракта и сахаров опреАелим из формулы (7), которая Аля нашего случая, при $\alpha=15,56$ (табц. 2), имеет виА:

ААЯ массовой концентрации экстракта

$$
\begin{aligned}
\ni= & 278,7-(25,2-10) \times 15,56= \\
& 278,7-236,5 \cong 42,2 \text { г } / \mathrm{AM}^{3}
\end{aligned}
$$

и массовой концентрации сахаров

$\mathrm{C}=252-(25,2-10) \times 15,56=$

$$
252-236,5 \cong 15,5 \text { г/AM }{ }^{3} \text {. }
$$

Концентрация спирта, соответственно, с учетом вариабельности коэффициента выхода спирта из еАиницы сахаров, составит:

$$
\begin{aligned}
\left(\mathrm{C}_{0}-\mathrm{C}\right) \times 0,6= & (252-15,5) \times(0,06+0,001)= \\
& (14,2+0,3) \% \text { об. }
\end{aligned}
$$

\section{Выводы}

Суммируя вышесказанное, можно закмючить, что снижение показаний сахарной шкамы рефрактометра при спиртовом брожении винограАного сусла пропорционацьно комичеству выброженных редуцирующих сахаров, опредеменных по ГОСТ 13192-73, с инкрементом, который зависит от начацьного содержания экстрактивных веществ Ао брожения, и Аця контроця содержания общего экстракта и массовой концентрации сахаров в процессе спиртового брожения возможно использование показаний сахарной шкацы рефрак-
Таблица 2. Зависимость исходной массовой концентрации сахаров в сусле - $\mathrm{C}_{0}$ и значение

\begin{tabular}{|c|c|c|c|c|c|c|c|c|}
\hline $\mathrm{B}_{0}$ & $\mathrm{C}_{0}$ & $\alpha$ & $\mathrm{B}_{0}$ & $\mathrm{C}_{0}$ & $\alpha$ & $\mathrm{B}_{0}$ & $\mathrm{C}_{0}$ & $\alpha$ \\
\hline 10,0 & 82 & 14,16 & 16,8 & 155 & 14,76 & 23,6 & 233 & 15,41 \\
\hline 10,2 & 84 & 14,17 & 17,0 & 158 & 14,78 & 23,8 & 235 & 15,43 \\
\hline 10,4 & 86 & 14,19 & 17,2 & 160 & 14,80 & 24,0 & 238 & 15,44 \\
\hline 10,6 & 88 & 14,21 & 17,4 & 162 & 14,81 & 24,2 & 240 & 15,46 \\
\hline 10,8 & 90 & 14,23 & 17,6 & 164 & 14,83 & 24,4 & 242 & 15,48 \\
\hline 11,0 & 92 & 14,24 & 17,8 & 167 & 14,85 & 24,6 & 245 & 15,50 \\
\hline 11,2 & 94 & 14,26 & 18,0 & 169 & 14,87 & 24,8 & 247 & 15,52 \\
\hline 11,4 & 97 & 14,28 & 18,2 & 171 & 14,89 & 25,0 & 249 & 15,54 \\
\hline 11,6 & 99 & 14,29 & 18,4 & 173 & 14,91 & 25,2 & 252 & 15,56 \\
\hline 11,8 & 101 & 14,31 & 18,6 & 176 & 14,93 & 25,4 & 254 & 15,58 \\
\hline 12,0 & 103 & 14,33 & 18,8 & 178 & 14,94 & 25,6 & 256 & 15,60 \\
\hline 12,2 & 105 & 14,35 & 19,0 & 180 & 14,96 & 25,8 & 259 & 15,62 \\
\hline 12,4 & 107 & 14,36 & 19,2 & 182 & 14,98 & 26,0 & 261 & 15,64 \\
\hline 12,6 & 109 & 14,38 & 19,4 & 185 & 15,00 & 26,2 & 263 & 15,66 \\
\hline 12,8 & 112 & 14,40 & 19,6 & 187 & 15,02 & 26,4 & 266 & 15,68 \\
\hline 13,0 & 114 & 14,42 & 19,8 & 189 & 15,04 & 26,6 & 268 & 15,71 \\
\hline 13,2 & 116 & 14,43 & 20,0 & 192 & 15,06 & 26,8 & 270 & 15,73 \\
\hline 13,4 & 118 & 14,45 & 20,2 & 194 & 15,08 & 27,0 & 273 & 15,75 \\
\hline 13,6 & 120 & 14,47 & 20,4 & 196 & 15,10 & 27,2 & 275 & 15,77 \\
\hline 13,8 & 122 & 14,49 & 20,6 & 198 & 15,11 & 27,4 & 277 & 15,79 \\
\hline 14,0 & 125 & 14,51 & 20,8 & 201 & 15,13 & 27,6 & 280 & 15,81 \\
\hline 14,2 & 127 & 14,52 & 21,0 & 203 & 15,15 & 27,8 & 282 & 15,83 \\
\hline 14,4 & 129 & 14,54 & 21,2 & 205 & 15,17 & 28,0 & 284 & 15,85 \\
\hline 14,6 & 131 & 14,56 & 21,4 & 208 & 15,19 & 28,2 & 287 & 15,87 \\
\hline 14,8 & 133 & 14,58 & 21,6 & 210 & 15,21 & 28,4 & 289 & 15,89 \\
\hline 15,0 & 135 & 14,59 & 21,8 & 212 & 15,23 & 28,6 & 292 & 15,91 \\
\hline 15,2 & 138 & 14,61 & 22,0 & 215 & 15,25 & 28,8 & 294 & 15,93 \\
\hline 15,4 & 140 & 14,63 & 22,2 & 217 & 15,27 & 29,0 & 296 & 15,95 \\
\hline 15,6 & 142 & 14,65 & 22,4 & 219 & 15,29 & 29,2 & 299 & 15,97 \\
\hline 15,8 & 144 & 14,67 & 22,6 & 221 & 15,31 & 29,4 & 301 & 15,99 \\
\hline 16,0 & 147 & 14,69 & 22,8 & 224 & 15,33 & 29,6 & 303 & 16,01 \\
\hline 16,2 & 149 & 14,70 & 23,0 & 226 & 15,35 & 29,8 & 306 & 16,03 \\
\hline 16,4 & 151 & 14,72 & 23,2 & 228 & 15,37 & 30,0 & 308 & 16,06 \\
\hline 16,6 & 153 & 14,74 & 23,4 & 231 & 15,39 & - & - & - \\
\hline
\end{tabular}
коэффициента $\alpha\left(\mathrm{B}_{0}\right)$ от исходной массовой доли сухих веществ в сусле $\mathrm{B}_{0}$

Table 2. The dependence of the initial mass concentration of sugars in the grape must $C_{0}$ and the value of the coefficient $\alpha\left(B_{0}\right)$ on the initial mass fraction of dry substances in the grape must $\mathrm{B}_{0}$

тометра Ао и в процессе брожения, как ацьтернативы Аенсиметрическому методу.

Источник финансирования Не указан.

\section{Financing source}

Not specified. 
К вопросу применения рефрактометрии

ААя мониторинга процесса брожения сусла

\section{Конфликт интересов} Не заявцен.

\section{Conflict of interests} Not declared.

\section{Список литературы/ References}

1. Методы технохимического и микробиологического контроля в виноделии / Под ред. Гержиковой В. Г. - Симферополь: Таврида. - 2002. - 259 с.

[Methods of techno-chemical and microbiological control in winemaking / Ed. Gerzhikova V.G. Simferopol: Tavrida. 2002. 259 p. (in Russian)].

2. Русаков В.А. Расчет купажей: учебное пособие. - К.: УМК BO, 1989. - 147 c.

[Rusakov V.A. Raschet kupazhey: uchebnoe posobie [Wine blend calculation - manual]. K.: UMK VO. 1989. - 147 p. (in Russian)].

3. Вечер А.С. К применению прецизионной рефрактометрии в виноделии // Труды Краснодарского института пищевой промышленности, вып.18, 1958. - С.176-196.

[Vecher A.S. $K$ primeneniyu pretsizionnoy refraktometrii $v$ vinodelii [Revisiting precision refractometry in winemaking]. Trudyi Krasnodarskogo instituta pischevoy promyishlennosti. Vol.18. 1958. pp.176-196 (in Russian)].

4. Иоффе Б. В. Рефрактометрические методы химии. 3-е изд., перераб. - Л.: Химия, 1983. - 352 с.

[Ioffe B.V. Refractometric methods of chemistry. 3rd ed., Rev. Leningrad: Chemistry. 1983. 352 p. (in Russian)].

5. ГОСТ 28562-90 Продукты переработки плодов и овощей. Рефрактометрический метод определения растворимых сухих веществ. - М.: Стандартинформ. 2005. - 10 с.

[GOST 28562-90 Fruit and vegetable products. Refractometric method for determination of soluble solids content. Moscow: Standartinform. 2005. 10 p. (in Russian)].

6. ГОСТ 27198-87 Виноград свежий. Методы определения массовой концентрации сахаров. - М.: ИПК Издательство стандартов. 2000. - 8 с.

[GOST 27198-87 Fresh grapes. Methods for determination of mass concentration of sugars. Moscow: IPK Izdatelstvo standartov. 2000. 8 p. (in Russian)].

7. Сливкин А.И., Селеменев В.Ф., Суховерхова Е.А. Физи-
Тимофеев Р.Г.

ко-химические и биологические методы оценки качества лекарственных средств. Учеб. пособие / Под ред. В. Г. Артюхова, А. И. Сливкина. - Воронеж: ВГУ, 1999. - 368 с.

[Slivkin A.I., Selemenev V.F., Suhoverhova E.A. Physicochemical and biological methods for assessing the quality of medicines. Study guide / Ed. V. G. Artyukhova, A. I. Slivkina. Voronezh: VSU. 1999. 368 p. (in Russian)].

8. Березина Е.С., Киселева А.А., Филиппова Ю.В. Рефрактометрическое определение концентрации спирта в лекарственных формах // Вестник Пермской государственной фармацевтической академии. - №2. - 2007. - С.123-125.

[Berezina E.S., Kiseleva A.A., Filippova Yu.V. Refractometric determination of the concentration of alcohol in dosage forms. Vestnik Permskoj gosudarstvennoj farmacevticheskoj akademii [Bulletin of the Perm State Pharmaceutical Academy]. №2. 2007. pp. 123-125 (in Russian)].

9. Сборник основных правил, технологических инструкций и нормативных материалов по производству винодельческой продукции. Под ред. Саришвили Н.Г. - Москва: Пищепромиздат, 1998. - 244 с.

[Sbornik osnovnyih pravil, tehnologicheskih instruktsiy $i$ normativnyih materialov po proizvodstvu vinodelcheskoy produktsii. Pod red. Sarishvili N.G [Collection of fundamental principles, progress guidelines and standards on wine production]. Moskva: Pischepromizdat. 1998. 244 p. (in Russian)].

10. ГОСТ 13192-73 Вина, виноматериалы и коньяки. Метод определения сахаров. - М.: Стандартинформ. 2011. - 10 с.

[GOST 13192-73 Wines, wine materials and cognacs. Method of sugar determination. Moscow: Standartinform. 2011. 10 p. (in Russian)].

11. ГОСТ 32095-2013 Продукция алкогольная и сырье для ее производства. Метод определения объемной доли этилового спирта - М.: Стандартинформ. 2014. - 6 с.

[GOST 32095-2013 The alcohol production and raw material for it producing. Method of ethyl alcohol determination. Moscow: Standartinform. 2014. 6 p. (in Russian)].

ORCID ID:

Тимофеев Р.Г. https://orcid.org/0000-0002-6105-944X 